Research Article

\title{
Seepage Analysis on the Surface Layer of Multistage Filled Slope with Rainfall Infiltration
}

\author{
Bingxiang Yuan $\mathbb{D}^{1,2}$ Zengrui Cai, ${ }^{1}$ Mengmeng Lu, ${ }^{3}$ Jianbing Lv ${ }^{D},{ }^{1} \mathrm{Zhilei}^{\mathrm{Su}}{ }^{1}$ \\ and Zuqing Zhao' \\ ${ }^{1}$ School of Civil and Transportation Engineering, Guangdong University of Technology, Guangzhou 510006, China \\ ${ }^{2}$ State Key Laboratory for Geomechanics and Deep Underground Engineering, China University of Mining \& Technology, \\ Xuzhou 221116, China \\ ${ }^{3}$ State Key Laboratory for Geomechanics and Deep Underground Engineering, School of Architecture and Civil Engineering, \\ China University of Mining and Technology, Xuzhou 221008, China \\ Correspondence should be addressed to Jianbing Lv; 2910515169@qq.com
}

Received 28 July 2020; Revised 11 August 2020; Accepted 11 August 2020; Published 26 August 2020

Academic Editor: Hang Lin

Copyright (c) 2020 Bingxiang Yuan et al. This is an open access article distributed under the Creative Commons Attribution License, which permits unrestricted use, distribution, and reproduction in any medium, provided the original work is properly cited.

\begin{abstract}
Based on the theory of rainfall infiltration, the surface infiltration model of multilevel filled slope was established by using the SEEP/W module of GeoStudio. The changes of the volumetric water content (VWC) and pore water pressure (PWP) in the surface of the slope during the rainfall infiltration were analyzed, and the influence of the change of the rainfall conditions on the VWC and PWP was considered. The analysis showed that VWC and PWP increased when the rain fell, and the growth rate of the higher feature point was higher. The affected area was concentrated on the upper part of the surface about $0.75 \mathrm{~m}$. With the increasing of rainfall intensity, the slope surface getting to transient saturation state was quick, and the time of the PWP increasing to 0 among the feature points of same elevation was shortened. Meanwhile, the PWP presented a positive value, and as the infiltration depth increased, the transient saturation region expanded. The safety coefficient of the multistage filled slope was continuously reduced; after the stop of rainfall, the VWC and the PWP decreased, and the decline rate of the higher feature points was higher. In addition, the PWP of the lower part increased, and the safety factor of the slope presented a trend of rebound.
\end{abstract}

\section{Introduction}

Rainfall is a major factor in causing slope accidents. The landslide disaster induced by rainfall infiltration poses a great threat to life and property of residents [1]. 28 people were killed, and 30 people disappeared in early April of 2017, Ponorogo county, Indonesia, after a landslide triggered by heavy rainfall. In late June of the same year, the mountain collapsed suddenly in Xinmo village. China, resulted in a river channel blockage which is 2,000 meters long; 10 people were killed, and 73 people were missing. Rainfall infiltration and runoff on the slope are the major factors leading to landslides, because they destroy the stability of the slope and reduce the safety factor of the slope, which leads to the occurrence of landslides. [2-4]. If the soil of the slope has good permeability and the rain infiltrates deeply, the shear strength of the slope will decrease, and the overall sliding instability will easily occur $[5,6]$.

In addition, during the rainfall process, rainwater seeps into the slope and the slope gradually form a transient saturated zone. The matric suction gradually decreases, which reduces the shear strength of the soil in the affected area of the slope, increases the load of the soil, and increases the risk of slope instability [7-9].

Therefore, scholars studied the stability and seepage characteristics of slope soil under rainfall conditions through laboratory model tests [10-13] and finite element software analysis [14-16]. Some scholars conducted a lot of research work on different research objects, such as loess [17-19], expansive soil [20,21], fractured rock mass [22], and granite 
residual soil $[23,24]$, and considered the influence of different factors, such as internal friction angle $[25,26]$, volumetric water content [27-29], hydraulic conductivity [30], and rainfall duration and intensity $[31,32]$.

Due to the large exposed area of multilevel fill slope, the influence of rainfall is more obvious, and the former people have less involvement in this object. Therefore, based on the multistage fill slope engineering example, the variation of surface water content and PWP of multistage fill slope during rainfall infiltration process were analyzed by SEEP/W module of GeoStudio, and the effects of rainfall on VWC and PWP were studied in this paper. Besides, the variation of safety factor of multistage high fill slope during rainfall was analyzed.

\section{Establishment of Surface Seepage Model of Slope}

Based on a multistage fill slope project in Guangzhou, this multistage fill slope was divided into four grades, and the gradient of each grade is 1:1.5. The slope was mainly filled with silty clay which caused the smallness of the hydraulic conductivity of the slope $[33,34]$. Therefore, the depth of the slope was less affected by rainfall. So, this paper mainly studied the seepage effect of rainwater on the surface soil of the slope. In order to visually to show the change of PWP and water content with the surface layer of slope under different rainfall conditions, a $2 \mathrm{D}$ model was built by the SEEP/W module of GeoStudio, and seepage analysis was carried out on some feature points of this model. The detailed dimensions and mesh division of this model was shown in Figure 1.

\subsection{Model Parameter}

2.1.1. Boundaries Setting. The upper surface boundary of the model was defined as rainfall infiltration boundary. The rainwater was all infiltrated into the beginning of rainfall. When the rainfall was too heavy, some rainwater flowed along the surface and water was not allowed to accumulate on the surface. Side boundaries of the model were set as the boundary of fixed water level, and the bottom of the model was impervious.

2.1.2. Surface Unit Setting. When climate conditions changed in a short period of time, a finer mesh needed to be divided to deal with dramatic changed in boundary conditions. Therefore, a surface-layer element of 1 meter was used to simulate 1 meter of slope surface which locates at the toe of slope, as shown in Figure 2, for seepage field analysis.

2.1.3. Rainfall Condition Setting. Because the saturated permeability coefficient is small, the infiltration depth is not determined by the rainfall intensity but by the saturated permeability coefficient due to the short-term rainfall. Therefore, the infiltration depth will not change when the rainfall intensity is greater than the permeability coefficient. Therefore, the rainfall intensity is set at $14.4 \mathrm{~mm} / \mathrm{d}$ and

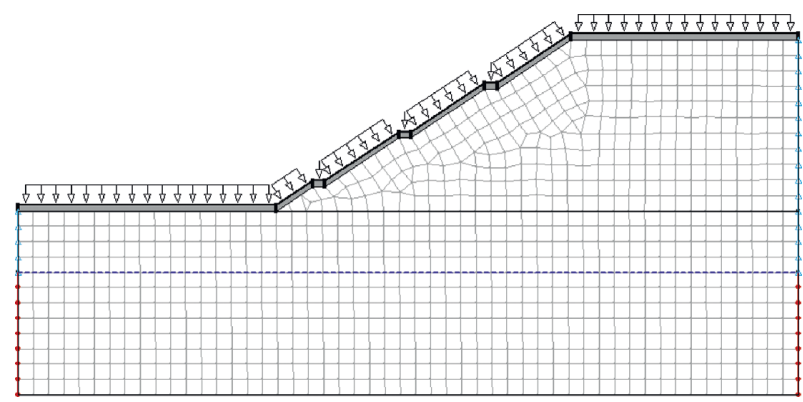

Figure 1: Boundary conditions and mesh of the model.

$6.8 \mathrm{~mm} / \mathrm{d}$ for 2 days. Simultaneously, the simulation lasted for 3 days from the start of rainfall.

\section{Initial Transient Seepage Field Setting}

The subsurface investigation into this project showed that the phreatic line was at $20 \mathrm{~m}$. According to the measured data and previous studies [35, 36], the maximum negative PWP above the phreatic line was $-20 \mathrm{kPa}$. The saturated VWC of soil below the phreatic line was 0.2 . The saturated hydraulic conductivity of filled soil was $4.8 \times 10^{-7} \mathrm{~m} / \mathrm{s}$. Since the original foundation was processed, it was assumed that its saturated hydraulic conductivity was the same as that of the filled soil. The distribution of PWP in the initial state of the slope was shown in Figure 3.

According to the Van-Genuchten and Nielsen method [37], the soil-water characteristic curve of the slope was determined, and then the permeability function curve was obtained. As shown in Figure 4, the hydraulic conductivity decreases with the increase of the matric suction, while the matric suction decreases with the increase of the VWC. Therefore, the VWC is an important factor affecting the hydraulic conductivity and the matric suction.

\section{Analysis of Seepage Results}

Based on the slope rainfall infiltration model, by analyzing the impact of different elevation, depth, rainfall intensity, and rainfall duration on the VWC and PWP of the slope to consider the safety factor of slope under different rainfall conditions.

\subsection{Effect of Rainfall Infiltration on Surface Water Content of} Slope. Before rainfall, the groundwater area in the lower part of the slope was saturated. According to the previous analysis, this area is basically not affected by rainfall infiltration. The corresponding VWC was saturated, and its size remained unchanged.

According to the theory of unsaturated soil, the infiltration of rainwater leads to the increase of VWC. Meanwhile, the matric suction of soil will decrease, the shear strength of soil will decrease, and the slope will lose stability.

During the rainfall infiltration process, the VWC of slope surface changes with time and elevation as shown in Figure 5. 


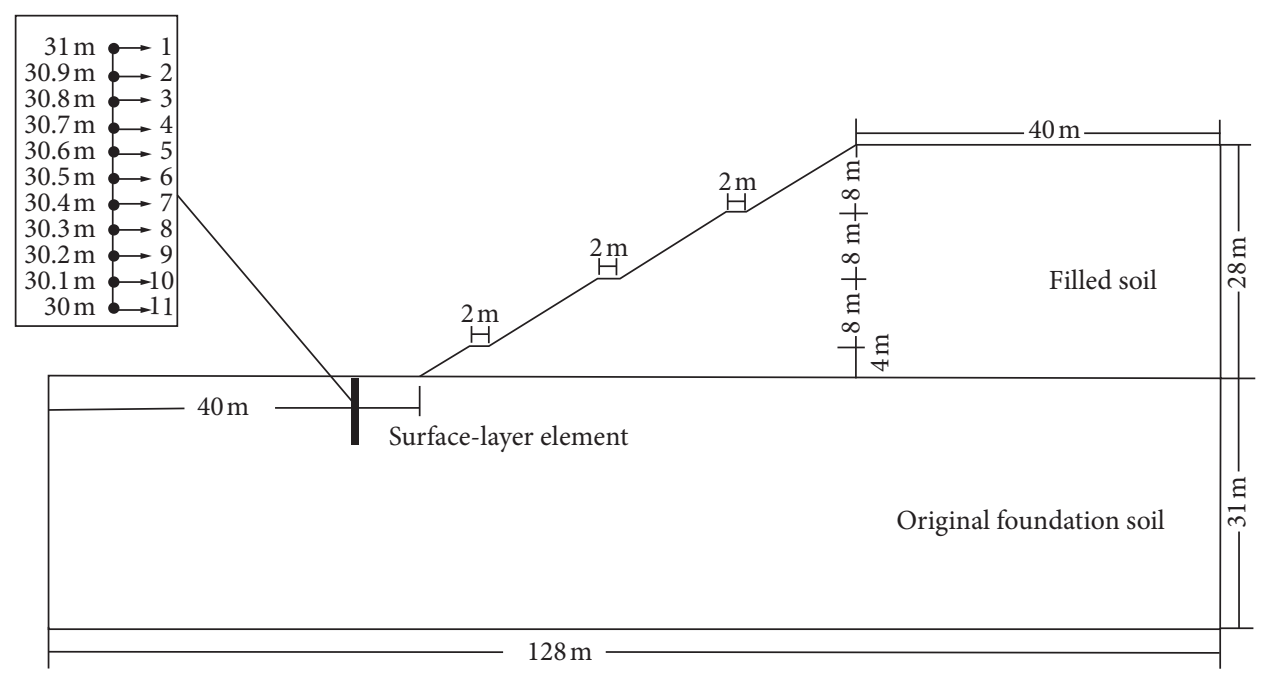

Figure 2: Location of surface-layer element and elevation corresponding to each feature point on the element.

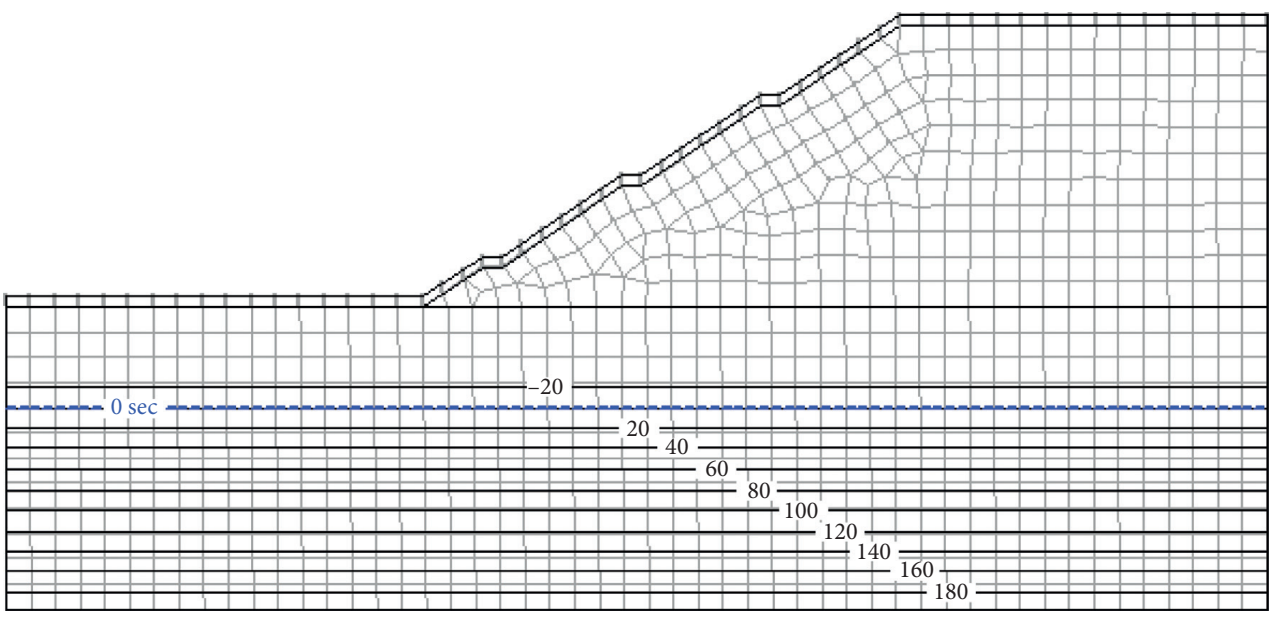

FIgURE 3: The distribution of initial PWP.

Figure 5(a) shows that the VWC changed immediately after the beginning of rainfall, and the VWC increased faster at the higher elevation. Furthermore, when the VWC of different elevations increases to 0.2 , the transient saturation zone occurs at the corresponding elevations. When it is at a certain depth, the VWC was not affected by rainfall. With the continuous infiltration of rainwater, the VWC of the feature points in higher elevation decreased faster after the stop of rainfall at 48th hour. As shown in Figure 5(b), the slope surface was affected obviously concentrated on the upper part of the surface of about $0.75 \mathrm{~m}$, and its influence degree decreases gradually with the increase of depth.

4.2. Influence of Rainfall Infiltration on PWP in the Surface of Slope. Before rainfall, soil at and below the groundwater level of slope was saturated; PWP increased linearly from zero with the increase of depth and was not affected by rainfall infiltration. The PWP was negative at the unsaturated state of the soil above the groundwater level of the slope.
According to the theory of unsaturated soil, rainwater infiltration leads to the increase of PWP, and at this time, the matric suction will decrease. So, the shear strength of the soil in this area will decrease, which will easily lead to slope instability.

The variation on PWP in slope surface with time and elevation during rainfall infiltration was shown in Figure 6. As shown in Figure 6(a), with the beginning of rainfall, the higher the elevation is, the earlier the PWP changes, and the faster the PWP increases. The PWP is not affected by rainfall at a certain depth. Due to the continuous infiltration of rainwater, the PWP of the feature points at the upper part of the surface decreases in different extent, and the PWP of the feature points at the lower part increases in different extent after the stop of rainfall at 48th hour.

As can be seen from Figure 6(b), with the infiltration of rainfall, the feature points of higher elevation quickly reach the saturation state, and it means a transient saturation zone appears. When the rainwater continues to infiltrate, the PWP in the affected area increases gradually and becomes a positive value. The increase of PWP was faster at higher 


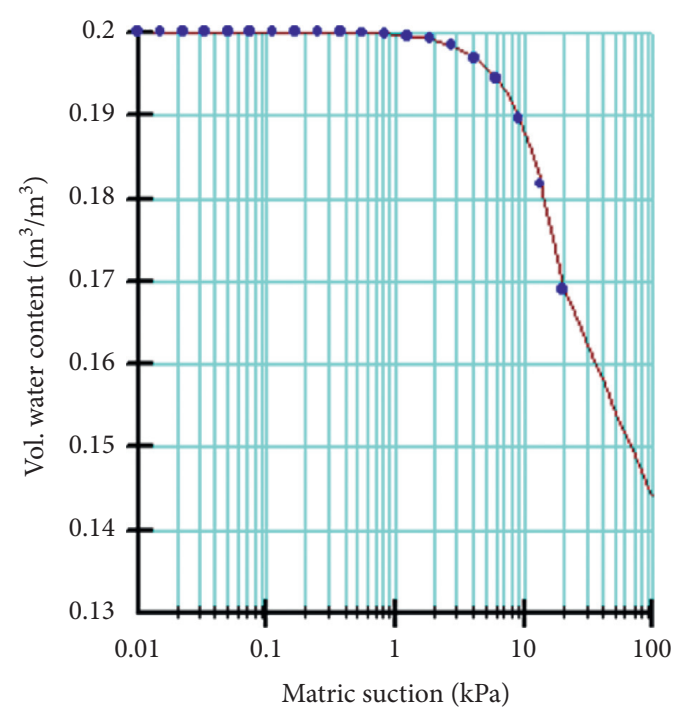

(a)

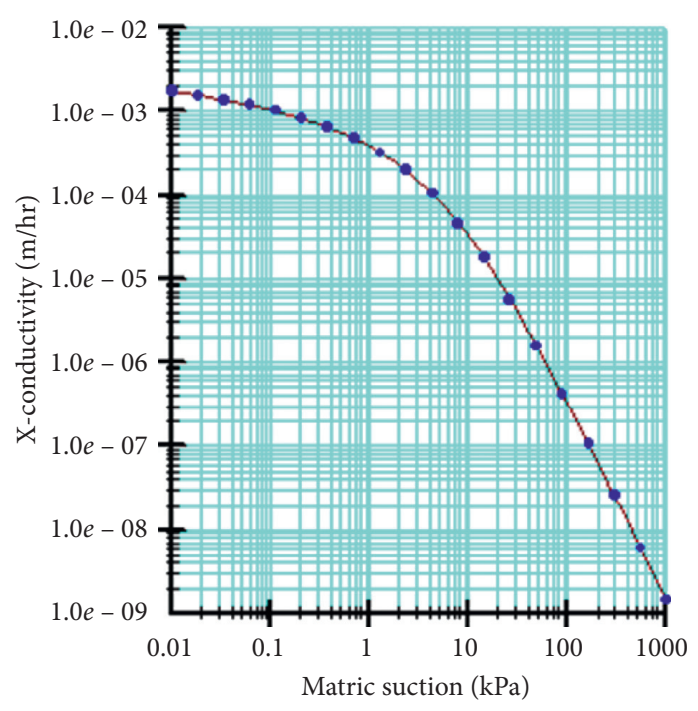

(b)

Figure 4: Soil property curve. (a) Soil-water characteristic curve. (b) Permeability function curve.

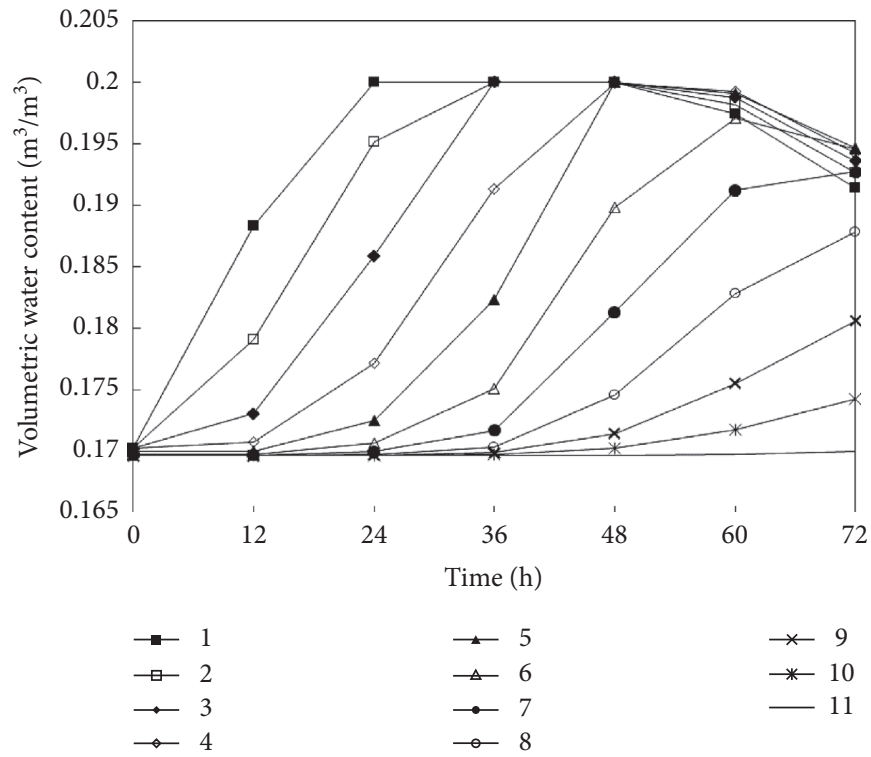

(a)

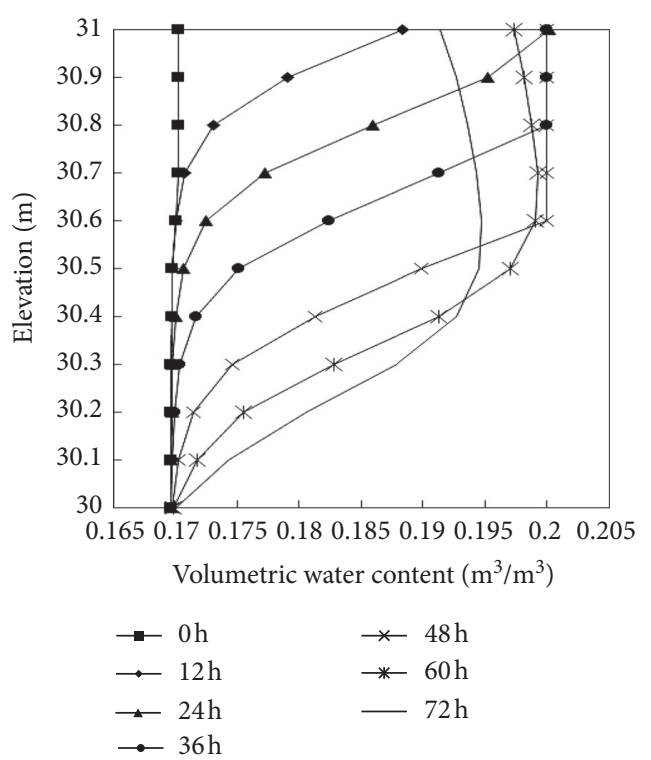

(b)

Figure 5: Influence parameters of volume water content on slope surface. (a) Time. (b) Elevation.

elevation and slower at lower elevation. When it reaches a certain depth, the PWP was not affected by rainfall. The affected area was also concentrated on the upper part of surface. After the stop of rainfall at 48th hour, the PWP in the upper part of the surface presents a downward trend and the PWP in the lower part of the surface increases with continuous infiltration of rainwater.

\subsection{Influence of Rainfall Conditions on Slope Surface} Infiltration. Rainfall conditions generally include rainfall intensity and duration. Next, the effect laws of different rainfall intensity and duration on the VWC and PWP of slope surface were analyzed.

4.3.1. Effect of Rainfall Intensity on VWC and PWP. The depth of infiltration is determined by the saturated hydraulic conductivity during short-term rainfall. And the infiltration depth would not change if the rainfall is stronger than the hydraulic conductivity. In order to study the effect of rainfall intensity on VWC and PWP, a comparison between two different rainfall intensities, $14.4 \mathrm{~mm} /$ day and $4.8 \mathrm{~mm} /$ day, which are less than saturated hydraulic conductivity, under 


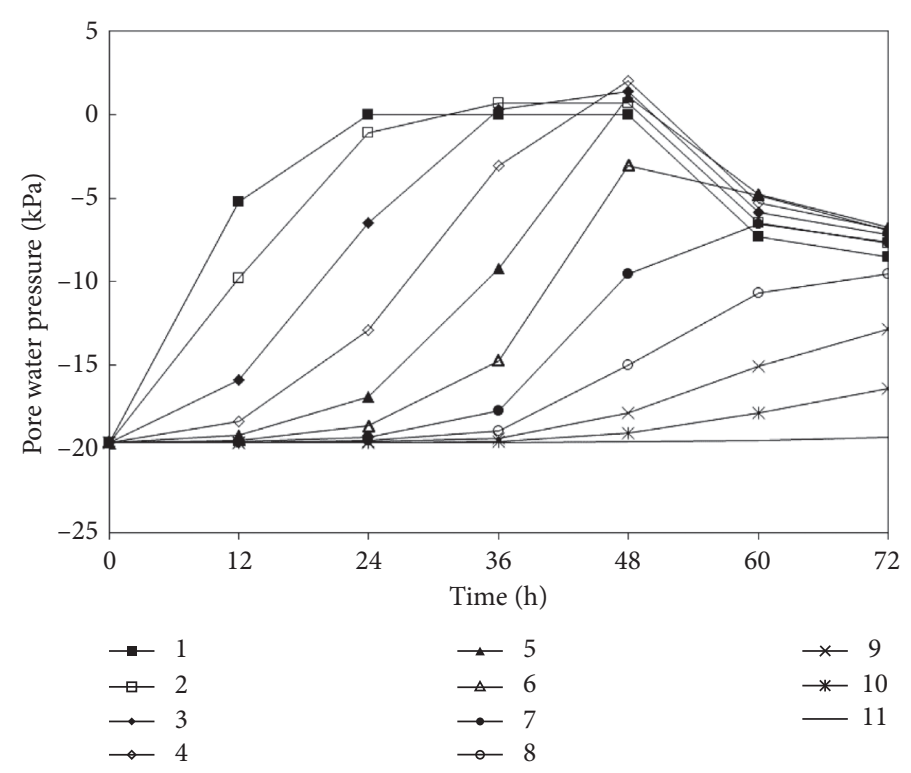

(a)

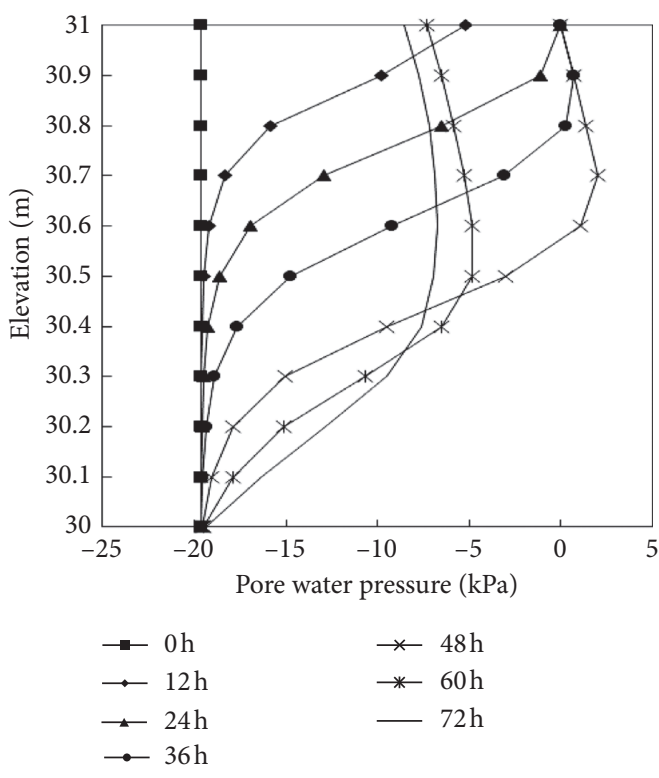

(b)

Figure 6: Influence parameters of PWP on slope surface. (a) Time. (b) Elevation.

the condition of 2 days of rainfall and 3 days of calculation duration, was analyzed.

In the case of two different rainfall intensities, VWC of the slope surface changes with elevation and time as shown in Figures 7 and 8, respectively. As shown in Figures 7 and 8, with the increase of rainfall intensity, the depth of the infiltration range of rain water deepens, and the characteristic points of surface transient saturation gradually increase. The infiltration depth of slope is $0.5 \mathrm{~m}$ and $0.7 \mathrm{~m}$, respectively. When the rainfall intensity was $4.8 \mathrm{~mm} /$ day, the slope VWC of every feature point in surface did not increase to saturation at the end of rainfall. When the rainfall intensity was $14.4 \mathrm{~mm} /$ day, feature point 1 of the slope surface increases in saturated VWC after $24 \mathrm{~h}$. This indicates that the larger the rainfall intensity is, the faster the increasing speed of the VWC of the feature points of the slope surface is. At the given time, the greater the rainfall intensity is, the more feature points affected by rainfall are, and the larger the influence scope is.

The PWP in the surface of the slope under two different rainfall intensities varies from elevation and time as shown in Figures 9 and 10; when the rainfall intensity was $4.8 \mathrm{~mm} /$ day, the PWP of the slope surface presents a negative value and does not reach to saturation state at the end of rainfall. When the rainfall intensity was $14.4 \mathrm{~mm} /$ day (as shown in Figure 9(b)), the PWP gradually reaches zero at higher elevation of the slope surface after 24 hours of rainfall. With the increase of the rainfall intensity, the PWP at the same elevation increases rapidly and then becomes a positive value. The main reason is that the rainwater from the slope surfaced to infiltrate into the toe of the slope. Then, a transient saturation zone on the surface occurs, and a small amount of rainwater remains in the soil pore. Furthermore, with the increase of rainfall intensity, the decreasing range of
PWP at each feature point increases after the stop of rainfall at 48th hour. The main reason is that the infiltration depth of rainfall is shallow, and the seepage effect is not obvious when the rainfall intensity is small.

When the rainfall intensity increases, the infiltration depth increases, and the transient saturated area expands. The existence of saturated area will accelerate the infiltration, leading to the continuous infiltration of upper rainwater and the absence of rainwater which is as a supplement. Therefore, the PWP will decrease, and the PWP of the lower affected feature points will increase with the increase of infiltration depth.

As shown in Figure 10, the time variation trend of PWP on the surface of slope was consistent under different rainfall intensities. With the increase of rainfall intensity, the feature points whose PWP reaches zero increased. Because the upper and middle parts of the slope converge to the toe of slope, some lesser positive values of PWP are generated at some feature points of the surface-layer element. Comparing with the growth rate of PWP at the condition of $4.8 \mathrm{~mm} /$ day rainfall intensity, the growth rate of PWP at each feature point of the surface-layer element was significantly faster at the condition of $14.4 \mathrm{~mm} /$ day rainfall intensity.

\subsubsection{Influence of Rainfall Duration on PWP and VWC.} This paper divides the duration of rainfall into two conditions: one was the same intensity of rainfall, different duration of rainfall; the other was the same total amount of rainfall, different duration of rainfall.

Condition 1. Under the rainfall intensity of $14.4 \mathrm{~mm} /$ day, analyze the impact of continuous rainfall every 12 hours on PWP and VWC, as shown in Figures 11 and 12. 


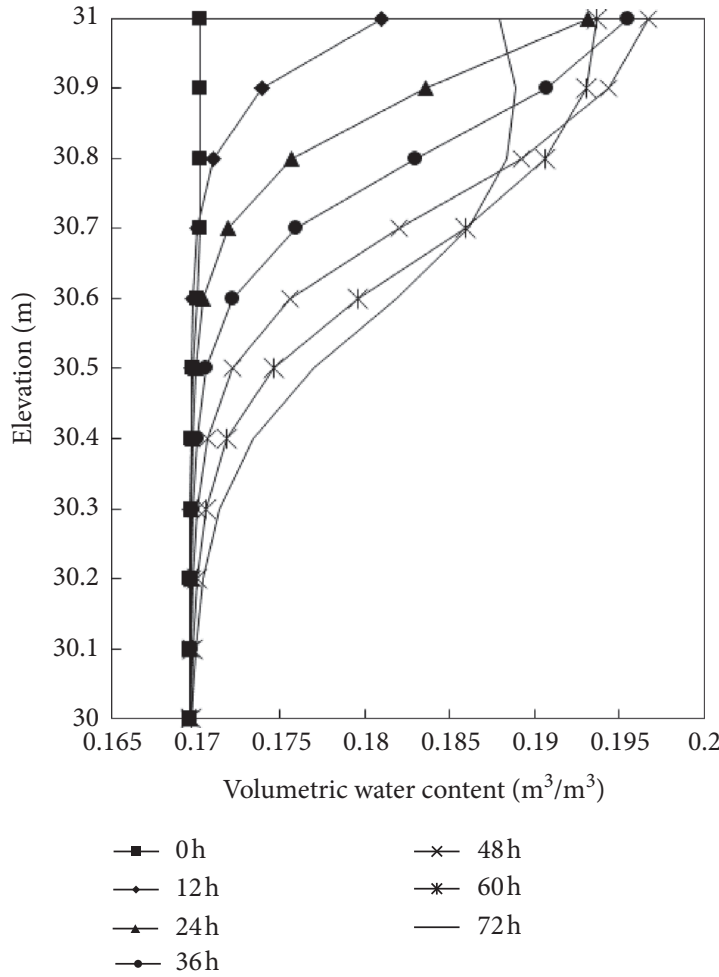

(a)

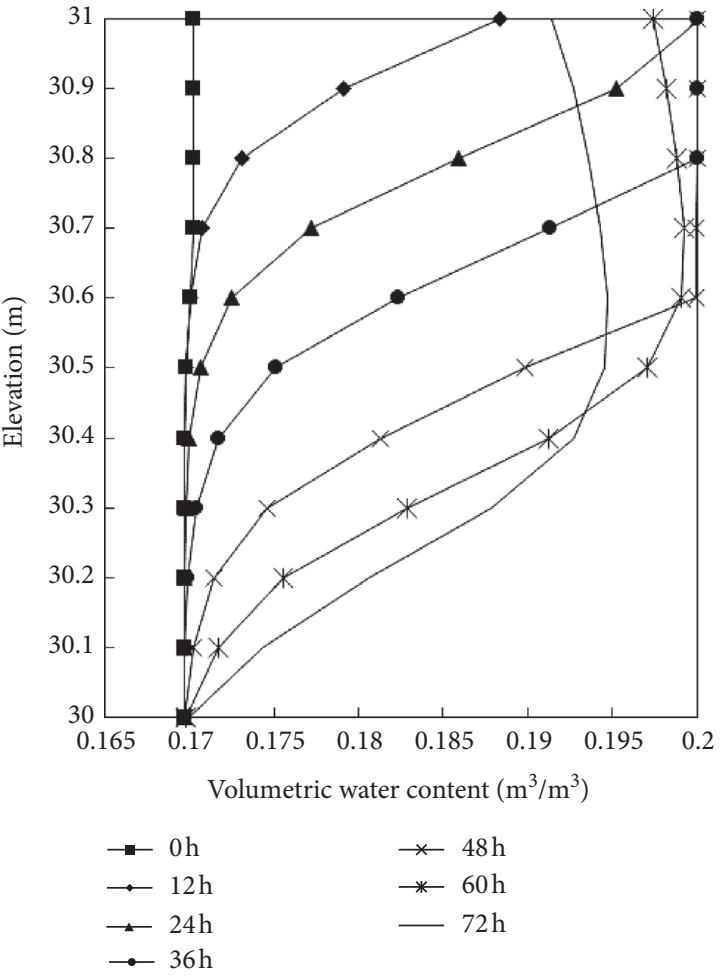

(b)

FIgURE 7: VWC and elevation under different rainfall intensities. (a) $4.8 \mathrm{~mm} /$ day. (b) $14.4 \mathrm{~mm} /$ day.

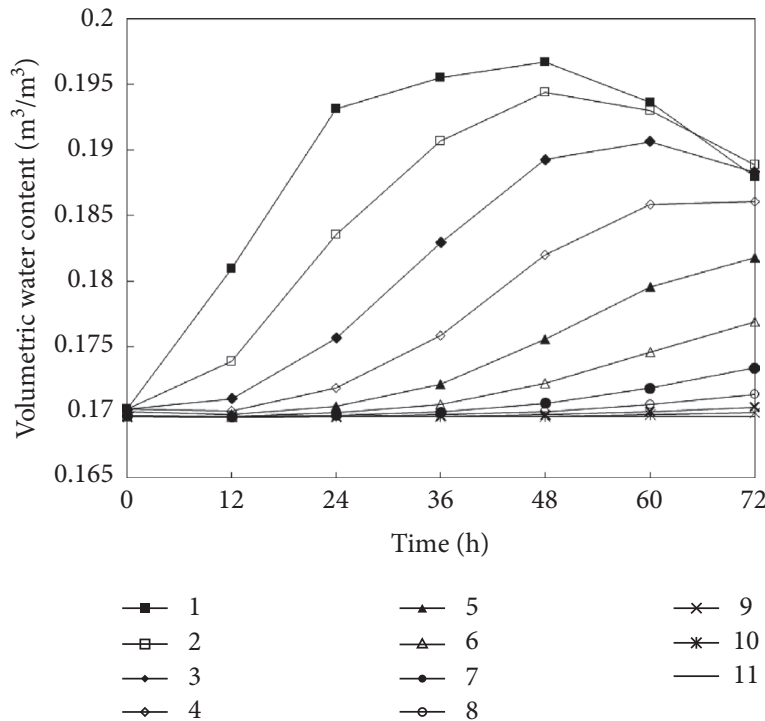

(a)

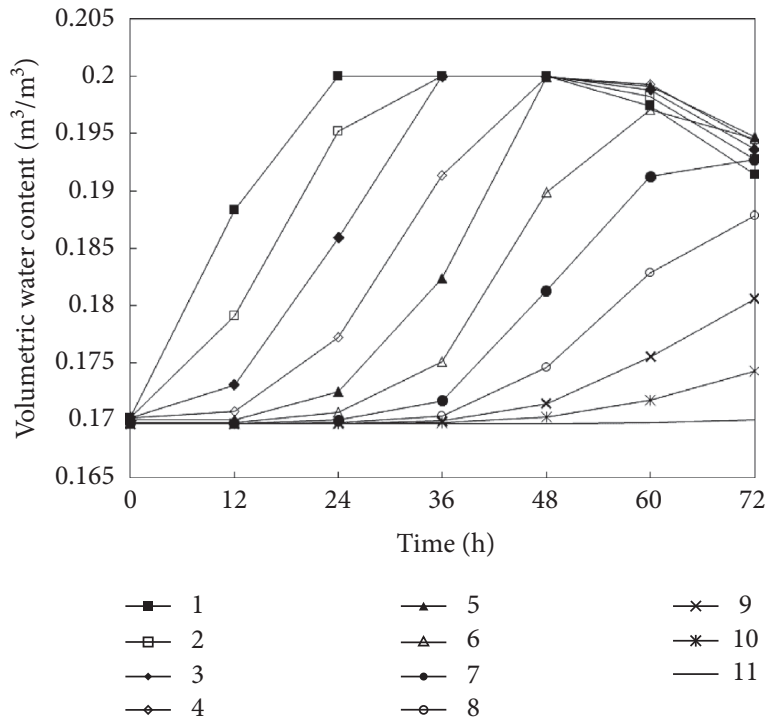

(b)

Figure 8: VWC and time under different rainfall intensities. (a) $4.8 \mathrm{~mm} /$ day. (b) $14.4 \mathrm{~mm} /$ day.

As shown in Figures 11 and 12, the variation trends of VWC and PWP are basically the same under different rainfall duration conditions. When rainfall intensity is constant, with the increase of rainfall time, the influence of rainfall on the matric suction of the slope surface is larger.
With the continuous rainfall time, the feature points of surface gradually reach the transient saturation state, and the PWP increases to zero. Positive values of PWP may occur in the slope surface because of the convergence of rainwater. The higher the elevation of the feature points is, the faster the 


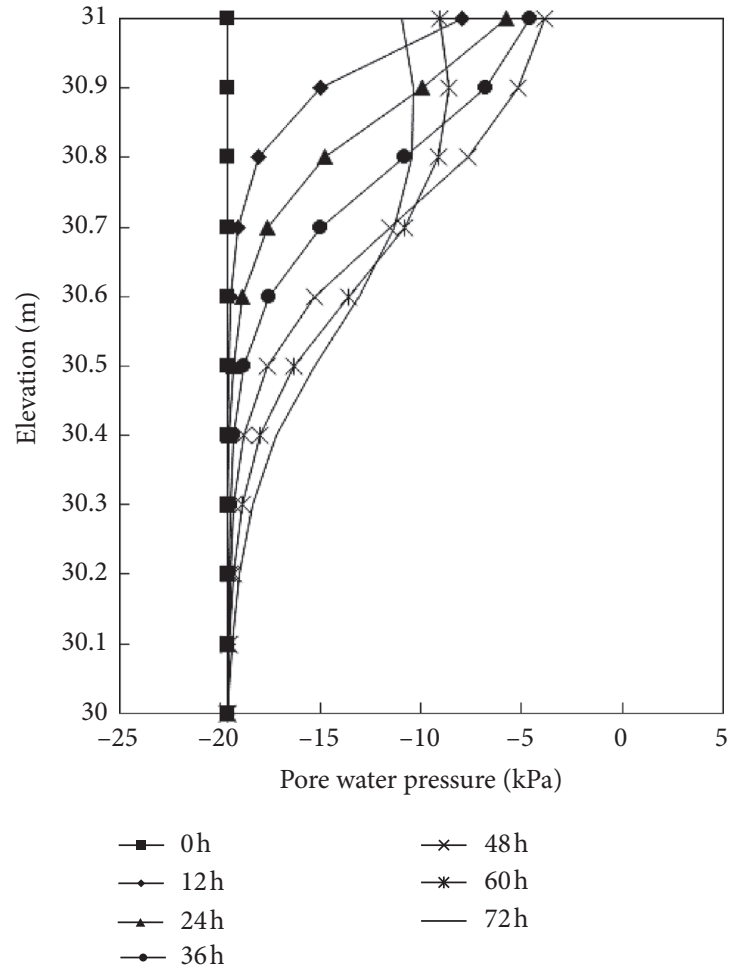

(a)

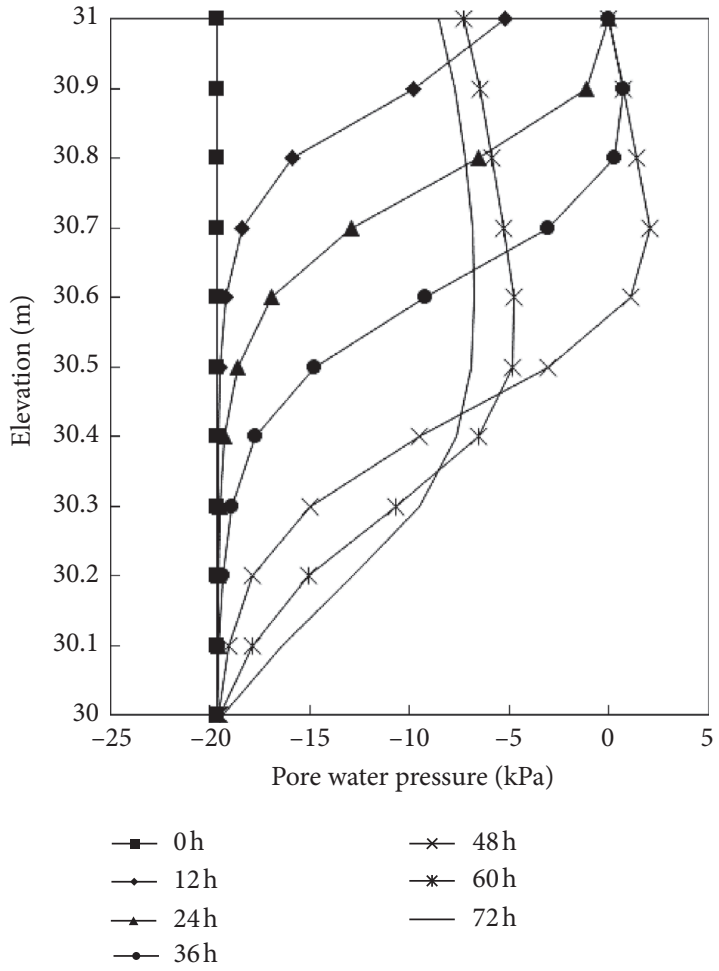

(b)

Figure 9: PWP and elevation under different rainfall intensities. (a) $4.8 \mathrm{~mm} /$ day. (b) $14.4 \mathrm{~mm} /$ day.

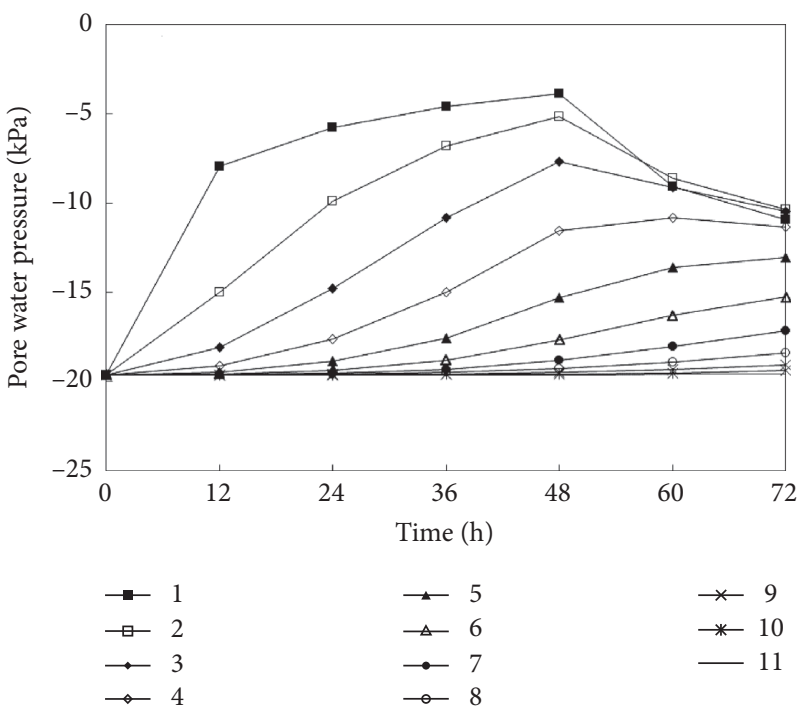

(a)

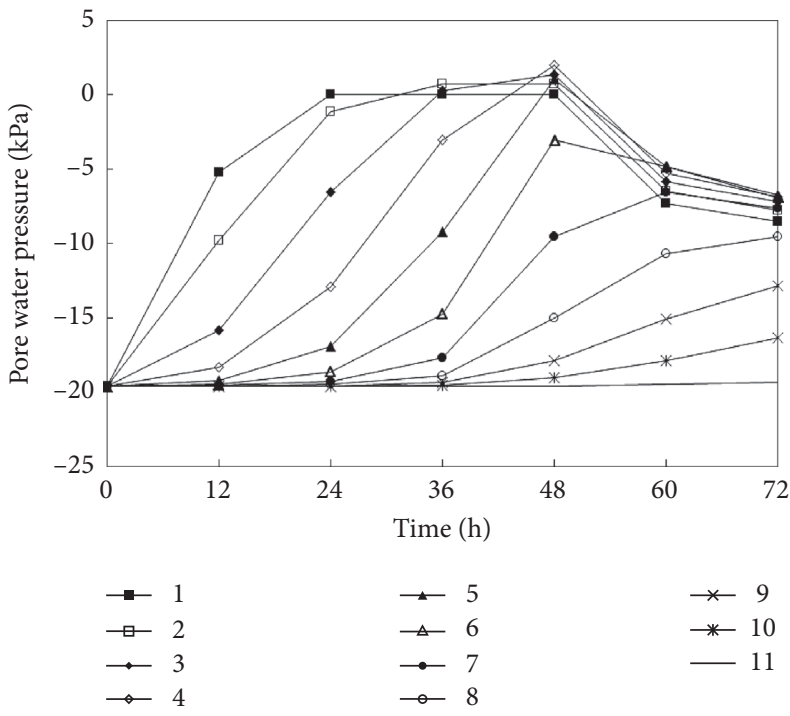

(b)

Figure 10: PWP and time under different rainfall intensities. (a) $4.8 \mathrm{~mm} /$ day. (b) $14.4 \mathrm{~mm} /$ day.

VWC reaches the saturated state, and so does the PWP rise to zero. The infiltration depth of the slope is about $0.4 \mathrm{~m}$ in one day of rainfall and $0.8 \mathrm{~m}$ in two days of rainfall. That is, when the rainfall intensity is constant and less than the saturated hydraulic conductivity, the longer the duration is, the greater the depth of influence is.
Condition 2. Considering that the rainfall is $14.4 \mathrm{~mm}$, the rainfall intensity is $4.8 \mathrm{~mm} / \mathrm{d}$ and $14.4 \mathrm{~mm} / \mathrm{d}$, respectively, and the rainfall duration is 1 day. Analyze the changes of VWC and PWP every 12 hours.

As shown in Figures 13 and 14, when the duration of rainfall is 3 days, the infiltration depth of rainwater is about 


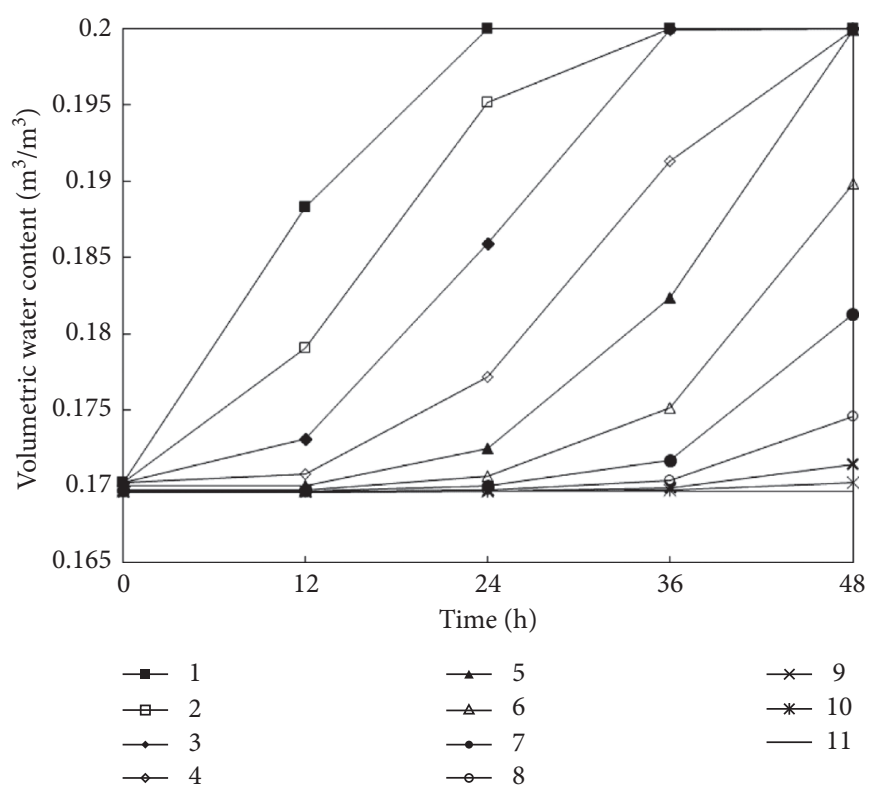

(a)

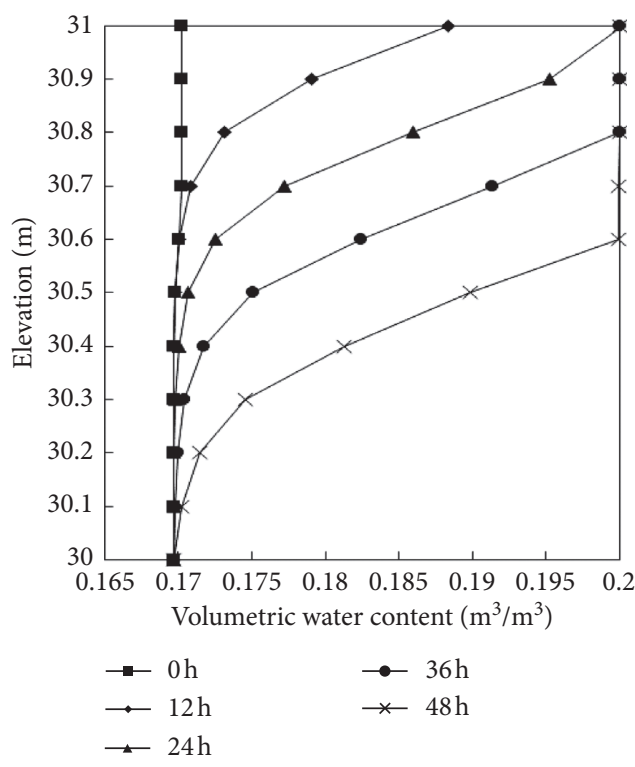

(b)

FIgUre 11: Parameters affecting VWC under the same rainfall intensity. (a) Time. (b) Elevation.

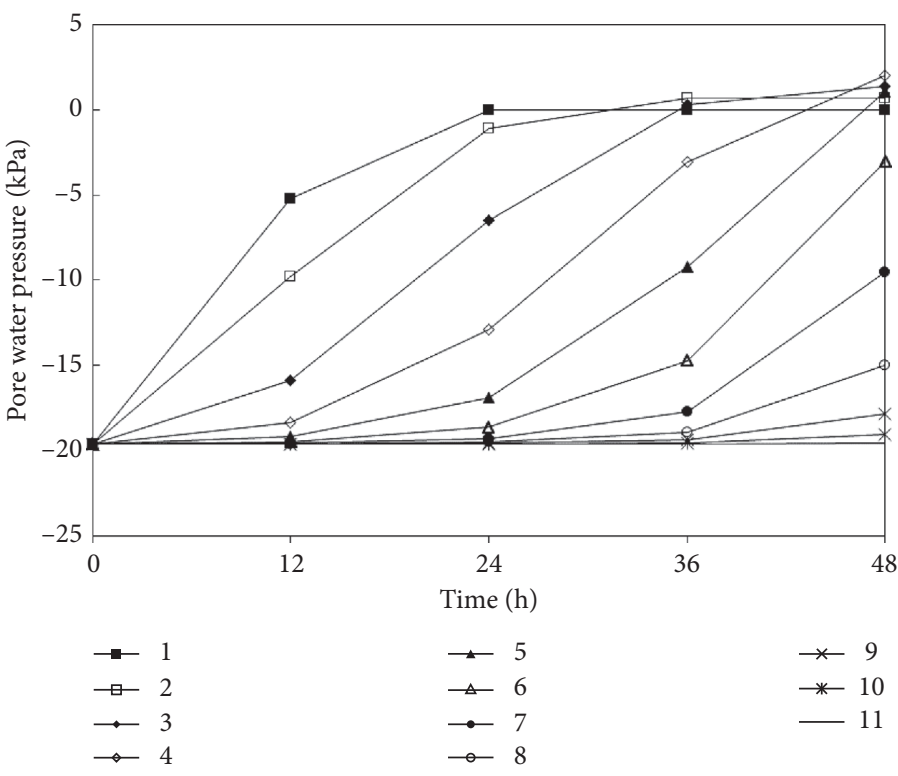

(a)

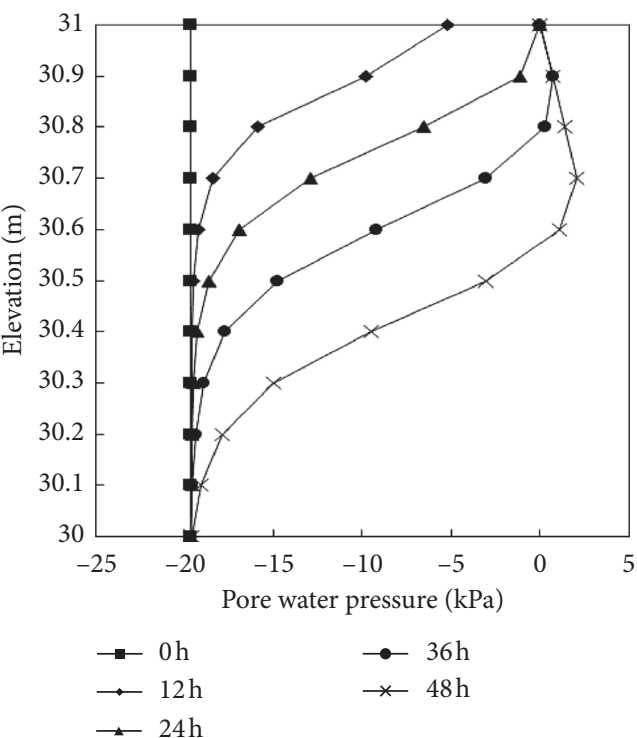

(b)

FIgUre 12: Parameters affecting PWP under the same rainfall intensity. (a) Time. (b) Elevation.

0.6-0.7 m; when the duration of rainfall is 1 day, the infiltration depth of rainwater is about $0.5 \mathrm{~m}$.

This indicates that with the same rainfall amount, the longer the duration of rainfall is, the greater the depth of rainwater infiltration is. The main reason is that most of the rain can gradually infiltrate into the soil when the rain intensity is low, and the duration is long. On the contrary, most of the rainwater fail to infiltrate in time.

As shown in Figures 15 and 16, when the rain intensity is low and the rainfall duration is long, the PWP of the feature points reaches zero slower, and the VWC of feature points reaches the saturated state slower. When the rainfall duration is three days, the feature points on the slope surface do not reach the transient saturation state. But when the rainfall duration is one day, the feature points reach the transient saturation state quickly.

4.4. The Influence of Rainfall Infiltration on the Stability. Rainfall infiltration causes variations in PWP and volume moisture content of the slope, which affect the stability of the slope to some extent. In this paper, the SEEP module of 


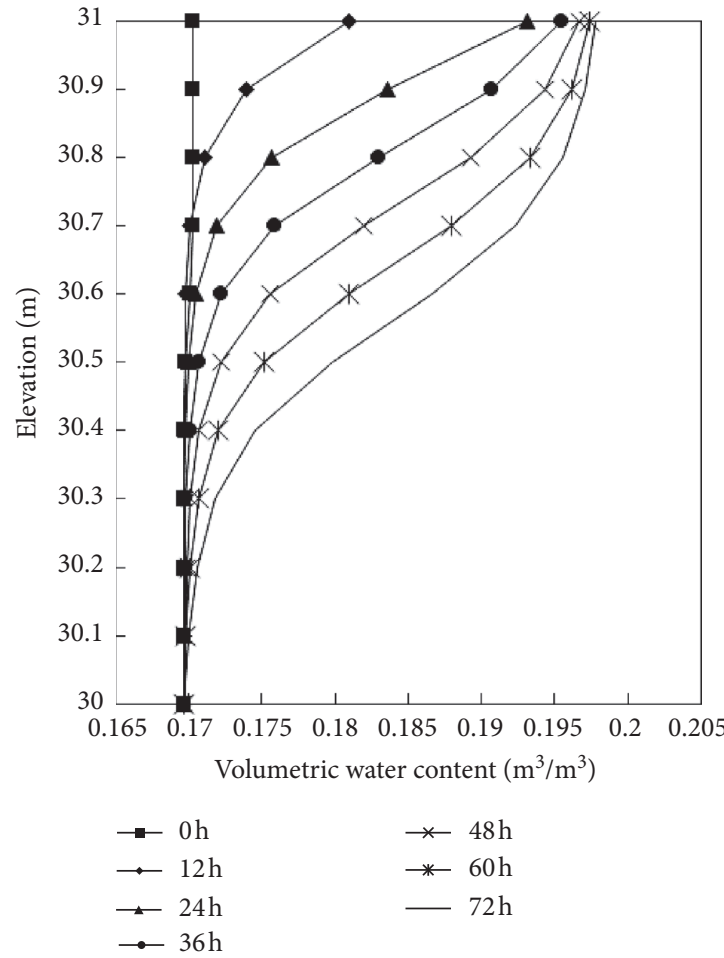

(a)

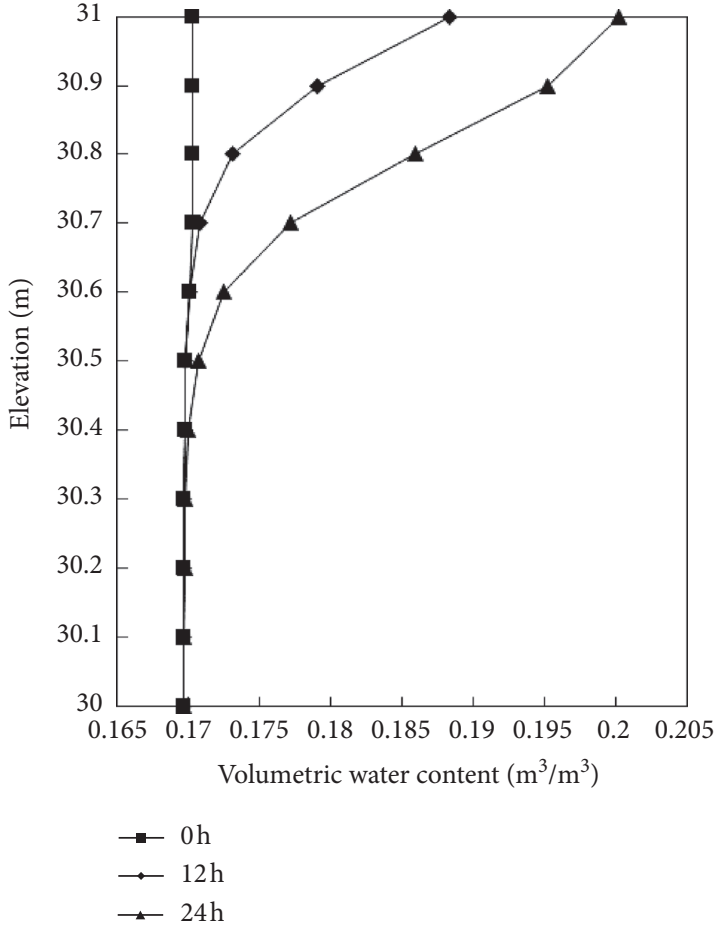

(b)

FIGURE 13: The VWC of the slope surface varies with elevation under different rainfall duration. (a) 3 days of duration. (b) 1 day of duration.

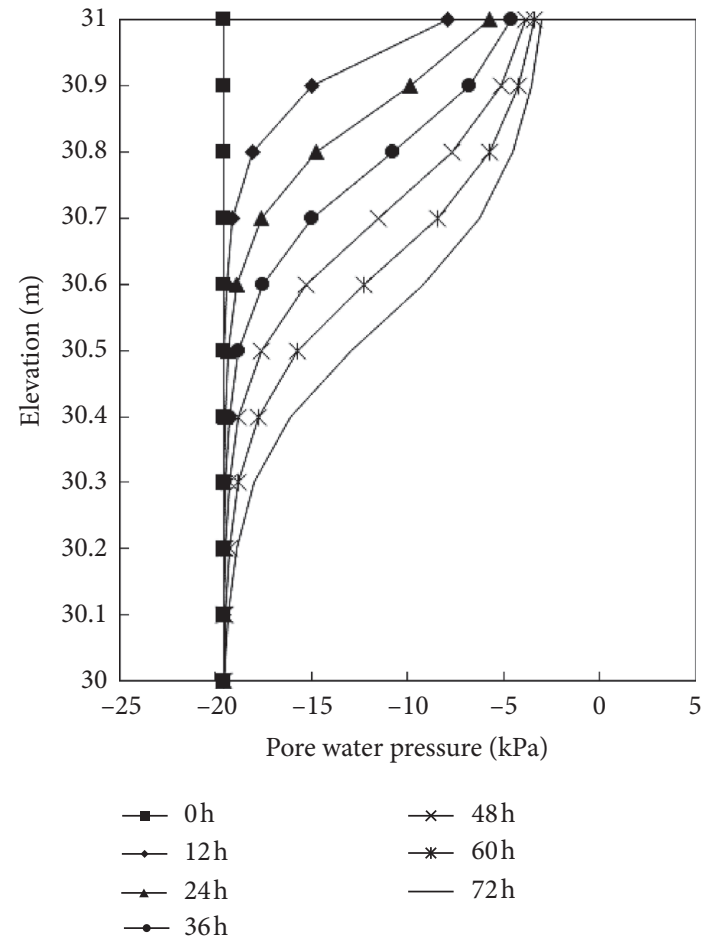

(a)

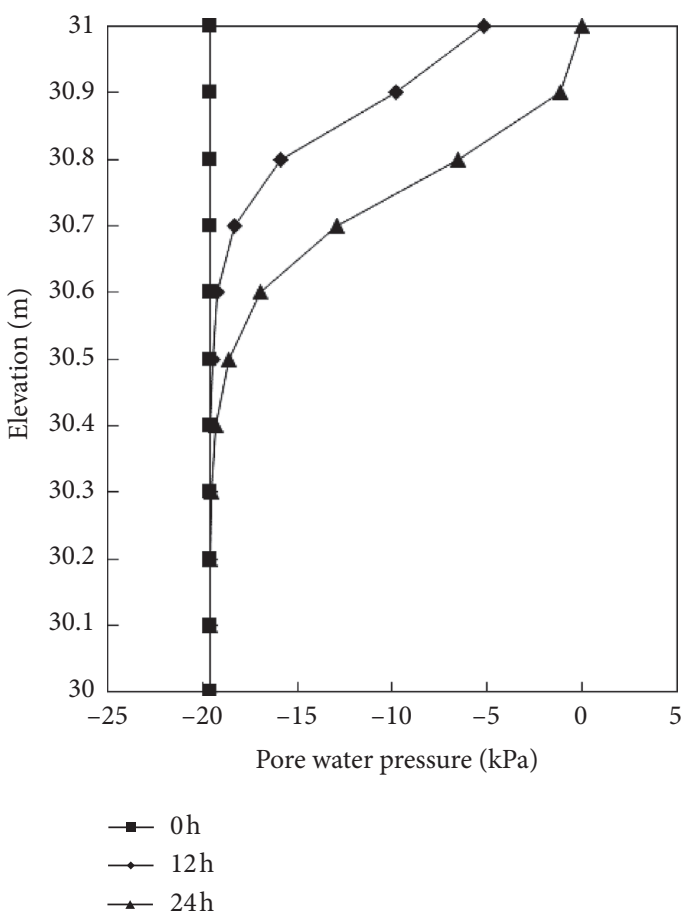

(b)

FIGURE 14: The PWP of the slope surface varies with elevation under different rainfall duration. (a) 3 days of duration. (b) 1 day of duration. 


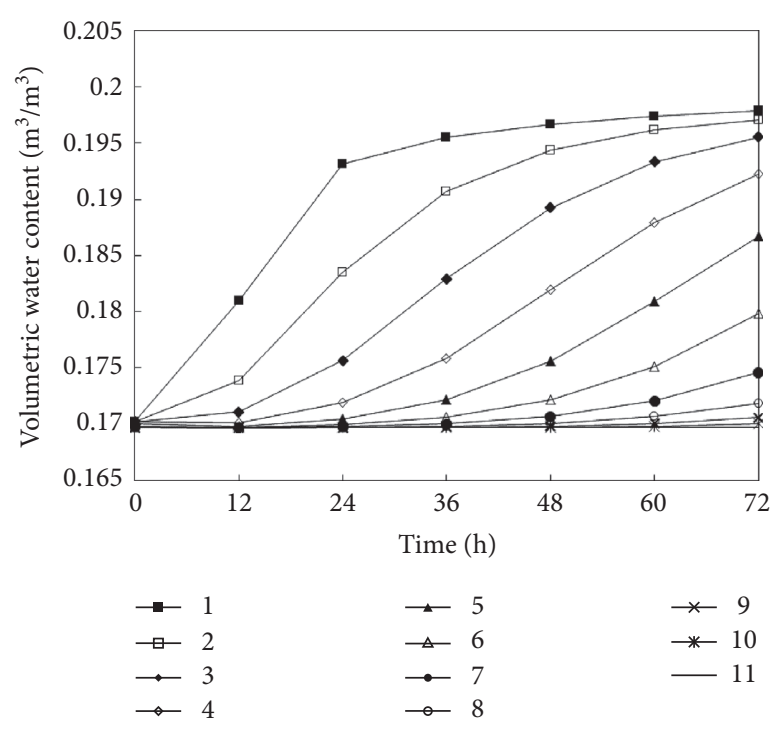

(a)

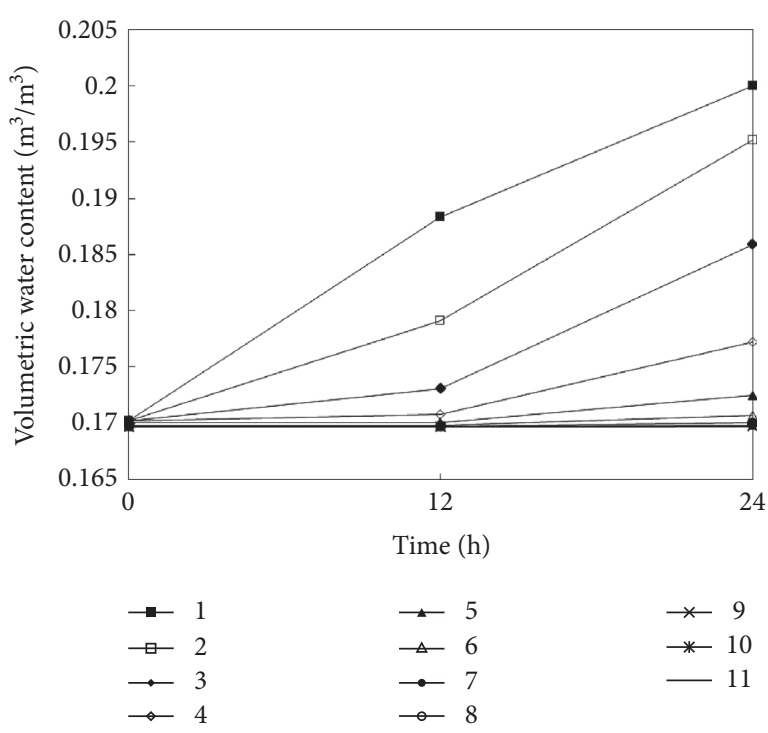

(b)

FIGURE 15: The VWC of the slope surface varies with time under different rainfall duration. (a) 3 days of duration. (b) 1 day of duration.

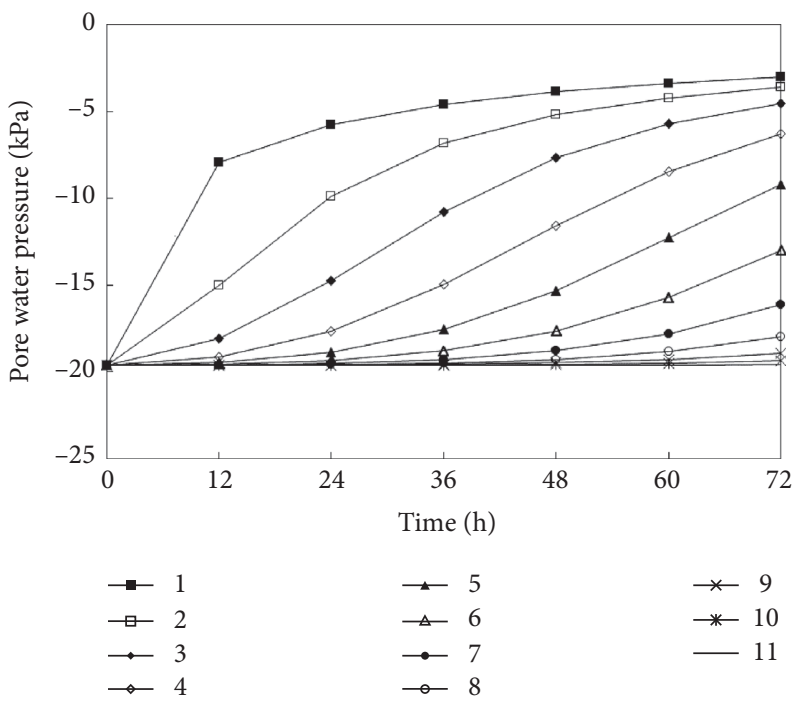

(a)

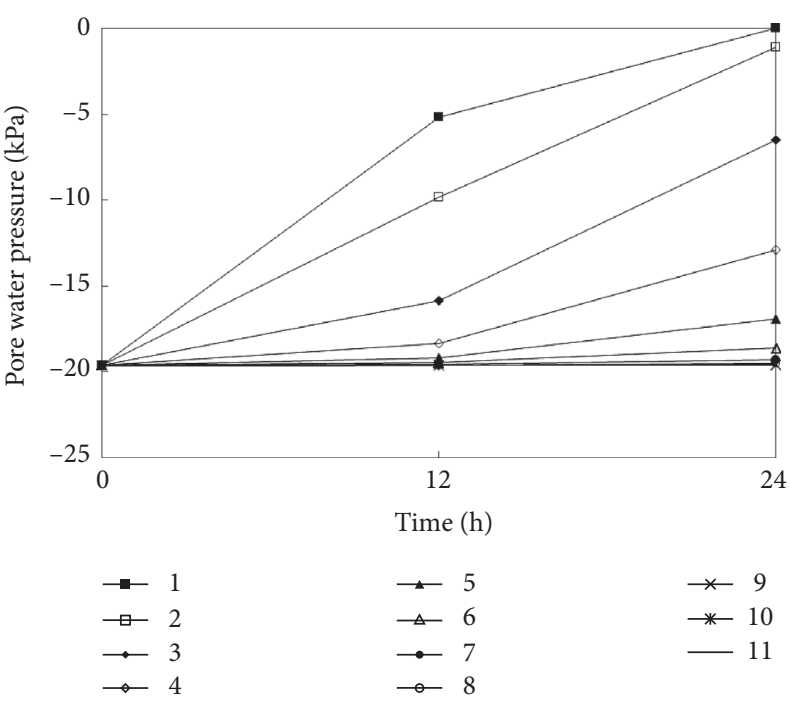

(b)

FIgUre 16: The PWP of the slope surface varies with time under different rainfall duration. (a) 3 days of duration. (b) 1 day of duration.

GeoStudio was combined with the SLOPE module to obtain the change of the safety factor of the slope after rainfall. The specific implementation process is shown in Figure 17.

The stability analysis was carried out for the rainfall intensities of $4.8 \mathrm{~mm} /$ day and $14.4 \mathrm{~mm} /$ day. The duration was 2 days, and the simulation lasted for 3 days. The safety factor of the slope changes as a function of time as shown in Figure 18.

As shown in Figure 18, the slope safety factor continues to decrease in the process of rainfall, and the decreasing range of the safety factor is different at different times. After the stop of rainfall, the safety factor presents a trend of recovery. The main reason is that water seepage causes the reduction of matric suction, and the shear strength is reduced, so the safety factor diminishes. Due to a certain hysteresis effect of rainfall, PWP does not change instantaneously, so the safety factor continues to decrease 12 hours after the stop of rainfall and then slightly increases from 12 hours to 24 hours after the rain stops.

Under two different rainfall intensities, the greater the rainfall intensity is, the greater the reduction of the safety factor during the rainfall process is. The main reason is that all the rainfall intensities were smaller than the saturated hydraulic conductivity of the slope, and all the rainwater infiltrated. When the rainfall duration is certain, the greater the rainfall intensity is, the greater the infiltration depth is, 


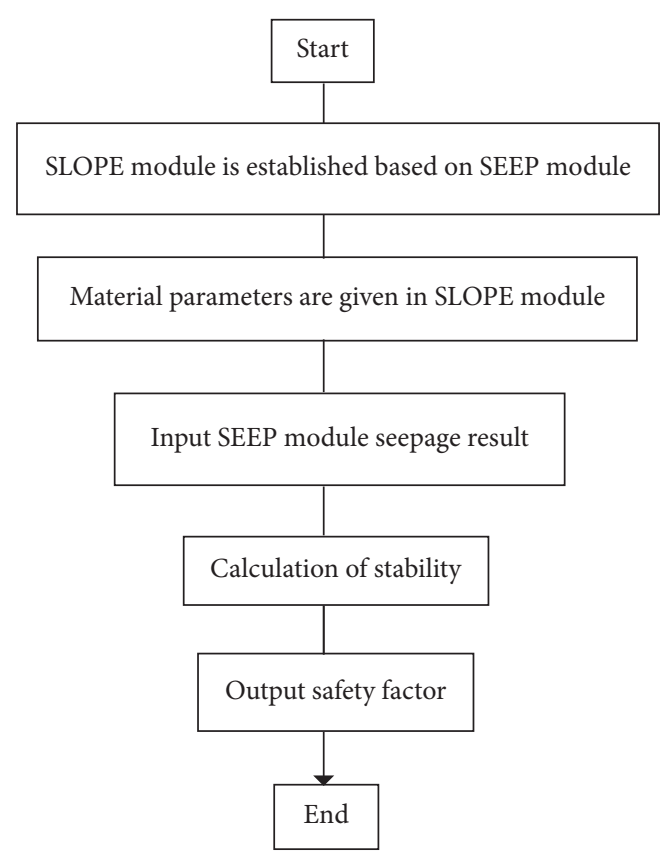

FIGURE 17: The flowchart of coupling analysis of SEEP and SLOPE modules.

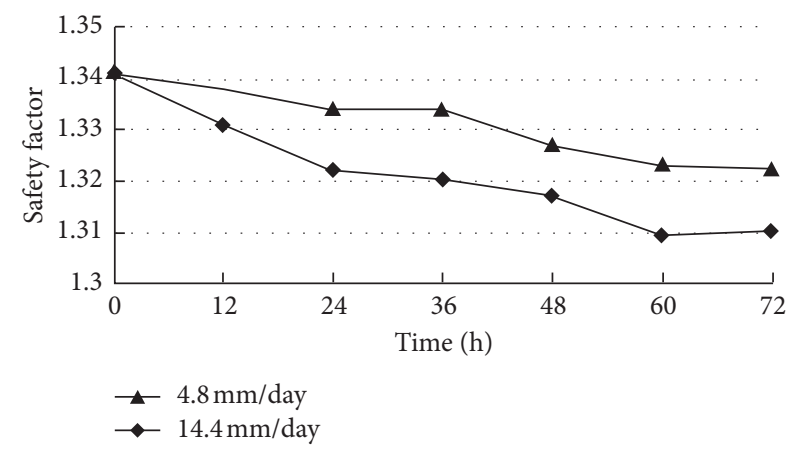

FIGURE 18: The variation curve of safety factor during rainfall.

the higher the slope water content is, and the smaller the matric suction is, so the decreasing range of the safety factor in the case of heavy rain is quite large.

\section{Conclusions}

Based on the basic theory of rainfall infiltration and combined with engineering example, this paper established the seepage model of multilevel filled soil slope and analyzed the surface infiltration law and studied the stability of slope by using the finite element method and limit equilibrium method. The following laws were obtained:

(1) After the start of rainfall, the VWC increased, and the higher the elevation was, the higher the growth rate was. When the depth reached a certain depth, the VWC was not affected by the rainfall. With rainfall infiltration, the PWP of the feature points at the slope surface first reached saturation state, and a transient saturation zone appeared. The PWP in the affected area gradually increased, and the higher the elevation was, the greater the growth rate was. Under a certain depth, the PWP was not affected by rainfall. After the stop of rainfall, the PWP of the lower part of the slope surface increased to some extent because of the continuous rainwater infiltration.

(2) In the case of different rainfall intensities, the greater the rain intensity was, the deeper the infiltration range of rain water was, and the number of feature points reaching the transient saturation state on the slope surface gradually increased, and the rate of those feature points reaching the transient saturation state on the section was also faster. When the rain intensity was less than the soil saturation hydraulic conductivity, the rain intensity increased, and the period of the PWP increase to zero was greatly shortened. The PWP may show lesser positive value. At the same time, the infiltration depth increased and resulted in the increase of the transient saturated region and the increase of the growth rate of PWP.

(3) The variation trends of VWC and PWP were basically the same under different rainfall duration. When the rainfall intensity was the same and less than the saturation hydraulic conductivity, with the increase of rainfall time, the slope surface matric suction was affected by rainfall in a larger range. With the same rainfall amount, the longer the duration of rainfall was, the greater the depth of rainwater infiltration was.

(4) In the process of rainfall, the safety factor of the slope decreased continuously, and the decreasing range of safety factor increased with the increase of rainfall intensity. After the stop of rainfall, the safety factor tended to rise.

\section{Data Availability}

The data used to support the findings of this study are included within the article.

\section{Conflicts of Interest}

The authors declare that they have no conflicts of interest regarding the publication of this paper.

\section{Acknowledgments}

The authors would gratefully like to acknowledge the support provided by the State Key Laboratory for Geomechanics and Deep Underground Engineering (SKLGDUEK1911), by the Science and Technology Plan Project of Guangdong Provincial Department of Transportation (2017-02-018), by the Natural Science Foundation of Guangdong Province (2018A030313839 and 2019A1515011397), and by the National Natural Science Foundation of China (51978177). The editorial help from Professor Galen Leonhardy of Black Hawk College is also greatly appreciated. 


\section{References}

[1] J. Chen, X. He, Z. Liu et al., "An approach to cross-calibrating multi-mission satellite data for the open ocean," Remote Sensing of Environment, vol. 246, Article ID 111895, 2020.

[2] R. Chen, R. Tan, Z. Chen, Y. Ping, and Z. Mei, "Influence of degree of compaction on unsaturated hydraulic properties of a compacted completely decomposed granite," Geofluids, vol. 2020, Article ID 7615361, 9 pages, 2020.

[3] S. Xie, H. Lin, Y. Chen, R. Yong, W. Xiong, and S. Du, "A damage constitutive model for shear behavior of joints based on determination of the yield point," International Journal of Rock Mechanics and Mining Sciences, vol. 128, Article ID 104269, 2020.

[4] F. B. Zhang, M. Y. Yang, B. B. Li, Z. B. Li, and W. Y. Shi, "Effects of slope gradient on hydro-erosional processes on an aeolian sand-covered loess slope under simulated rainfall," Journal of Hydrology, vol. 553, pp. 447-456, 2017.

[5] Y. Chen and H. Lin, "Consistency analysis of Hoek-Brown and equivalent Mohr-coulomb parameters in calculating slope safety factor," Bulletin of Engineering Geology and the Environment, vol. 78, no. 6, pp. 4349-4361, 2019.

[6] Y.-X. Wang, P.-P. Guo, W.-X. Ren et al., "Laboratory investigation on strength characteristics of expansive soil treated with jute fiber reinforcement," International Journal of Geomechanics, vol. 17, no. 11, Article ID 04017101, 2017.

[7] C. Andreea, "Unsaturated slope stability and seepage analysis of a dam," Energy Procedia, vol. 85, pp. 93-98, 2016.

[8] Y. Wang, P. Guo, F. Dai, X. Li, Y. Zhao, and Y. Liu, "Behavior and modeling of fiber-reinforced clay under triaxial compression by combining the superposition method with the energy-based homogenization technique," International Journal of Geomechanics, vol. 18, no. 12, Article ID 04018172, 2018.

[9] D. Zhou, Z. Zhang, J. Li, and X. Wang, "Seepage-stress coupled modeling for rainfall induced loess landslide," Theoretical and Applied Mechanics Letters, vol. 9, no. 1, pp. 7-13, 2019.

[10] R. Chen, J. Liu, C. W. W. Ng, and Z. K. Chen, "Influence of slope angle on water flow in a three-layer capillary barrier soil cover under heavy rainfall," Soil Science Society of America Journal, vol. 83, no. 6, pp. 1637-1647, 2019.

[11] M. S. Kim, Y. Onda, T. Uchida, J. K. Kim, and Y. S. Song, "Effect of seepage on shallow landslides in consideration of changes in topography: case study including an experimental sandy slope with artificial rainfall," Catena, vol. 161, pp. 5062, 2018.

[12] Y. X. Wang, S. B. Shan, C. Zhang, and P. P. Guo, "Seismic response of tunnel lining structure in a thick expansive soil stratum," Tunnelling and Underground Space Technology, vol. 88, pp. 250-259, 2019.

[13] B. Yuan, M. Sun, L. Xiong, Q. Luo, S. P. Pradhan, and H. Li, "Investigation of 3D deformation of transparent soil around a laterally loaded pile based on a hydraulic gradient model test," Journal of Building Engineering, vol. 28, no. 3, Article ID 101024, 2020.

[14] W. Wu, G. Jiang, S. Huang, G. Mei, and C. J. Leo, "A new analytical model to study the influence of weld on the vertical dynamic response of prestressed pipe pile," International Journal for Numerical and Analytical Methods in Geomechanics, vol. 41, no. 10, pp. 1247-1266, 2017.

[15] C. Yan and Y.-Y. Jiao, "A 2D fully coupled hydro-mechanical finite-discrete element model with real pore seepage for simulating the deformation and fracture of porous medium driven by fluid," Computers \& Structures, vol. 196, pp. 311-326, 2018.

[16] B. Yuan, K. Xu, Y. Wang, R. Chen, and Q. Luo, "Investigation of deflection of a laterally loaded pile and soil deformation using the PIV technique," International Journal of Geomechanics, vol. 17, Article ID 04016138, 2017.

[17] S. Naidu, K. S. Sajinkumar, T. Oommen, V. J. Anuja, R. A. Samuel, and C. Muraleedharan, "Early warning system for shallow landslides using rainfall threshold and slope stability analysis," Geoscience Frontiers, vol. 9, no. 6, pp. 1871-1882, 2018.

[18] W. Wu, M. H. El Naggar, M. Abdlrahem, G. Mei, and K. Wang, "New interaction model for vertical dynamic response of pipe piles considering soil plug effect," Canadian Geotechnical Journal, vol. 54, no. 7, pp. 987-1001, 2017.

[19] Y. Yu, J. Wang, C. Qiao, and G. Ou, "Numerical analysis unsaturated seepage of loess slope," Electronic Journal of Geotechnical Engineering, vol. 9, pp. 9729-9737, 2014.

[20] M. Lu, H. Jing, B. Wang, and K. Xie, "Consolidation of composite ground improved by granular columns with medium and high replacement ratio," Soils and Foundations, vol. 57, no. 6, pp. 1088-1095, 2017.

[21] S. Qi and S. K. Vanapalli, "Influence of swelling behavior on the stability of an infinite unsaturated expansive soil slope," Computers and Geotechnics, vol. 76, pp. 154-169, 2016.

[22] M. Lu, H. Jing, Y. Zhou, and K. Xie, "General analytical model for consolidation of stone column-reinforced ground and combined composite ground," International Journal of Geomechanics, vol. 17, no. 6, Article ID 04016131, 2017.

[23] K. Pham, D. Kim, H.-J. Choi, I.-M. Lee, and H. Choi, “A numerical framework for infinite slope stability analysis under transient unsaturated seepage conditions," Engineering Geology, vol. 243, pp. 36-49, 2018.

[24] A. M. S. Pradhan and Y.-T. Kim, "Application and comparison of shallow landslide susceptibility models in weathered granite soil under extreme rainfall events," Environmental Earth Sciences, vol. 73, no. 9, pp. 5761-5771, 2015.

[25] R. Chen, J. W. Huang, Z. K. Chen, Y. Xu, J. Liu, and Y. H. Ge, "Effect of root density of wheat and okra on hydraulic properties of an unsaturated compacted loam," European Journal of Soil Science, vol. 70, no. 3, pp. 493-506, 2019.

[26] K. Cui, G. Wu, Y. Du, X. An, and Z. Wang, "The coupling effects of freeze-thaw cycles and salinization due to snowfall on the rammed earth used in historical freeze-thaw cycles relics in northwest China," Cold Regions Science and Technology, vol. 160, pp. 288-299, 2019.

[27] S. E. Cho, "Prediction of shallow landslide by surficial stability analysis considering rainfall infiltration," Engineering Geology, vol. 231, pp. 126-138, 2017.

[28] A. P. Dyson and A. Tolooiyan, "Prediction and classification for finite element slope stability analysis by random field comparison," Computers and Geotechnics, vol. 109, pp. 117129, 2019.

[29] B. Yuan, M. Sun, Y. Wang, L. Zhai, Q. Luo, and X. Zhang, "Full 3D displacement measuring system for 3D displacement field of soil around a laterally loaded pile in transparent soil," International Journal of Geomechanics, vol. 19, no. 5, Article ID 04019028, 2019a.

[30] K. Meng, C. Cui, and H. Li, "An ontology framework for pile integrity evaluation based on analytical methodology," IEEE Access, vol. 8, pp. 72158-72168, 2020.

[31] C. Li, J. Zou, and A. Si-Ga, "Closed-form solution for undrained cavity expansion in anisotropic soil mass based on the 
spatially mobilized plane failure criterion," International Journal of Geomechanics, vol. 19, no. 7, Article ID 04019075, 2019.

[32] T. Yin, S. Zhang, X. Li, and L. Bai, "A numerical estimate method of dynamic fracture initiation toughness of rock under high temperature," Engineering Fracture Mechanics, vol. 204, pp. 87-102, 2018.

[33] A. Chueasamat, T. Hori, H. Saito, T. Sato, and Y. Kohgo, "Experimental tests of slope failure due to rainfalls using $1 \mathrm{~g}$ physical slope models," Soils and Foundations, vol. 58, no. 2, pp. 290-305, 2018.

[34] B. Yuan, L. Xiong, L. Zhai et al., "Transparent synthetic soil and its application in modeling of soil-structure interaction using optical system," Frontiers in Earth Science, vol. 7, p. 276, 2019.

[35] J. J. Ni, A. K. Leung, C. W. W. Ng, and W. Shao, "Modelling hydro-mechanical reinforcements of plants to slope stability," Computers and Geotechnics, vol. 95, pp. 99-109, 2018.

[36] T. Yin, L. Bai, X. Li, X. Li, and S. Zhang, "Effect of thermal treatment on the mode I fracture toughness of granite under dynamic and static coupling load," Engineering Fracture Mechanics, vol. 199, pp. 143-158, 2018.

[37] M. T. Van Genuchten and D. R. Nielsen, "On describing and predicting the hydraulic properties of unsaturated soils," Annales Geophysicae, vol. 3, no. 5, pp. 615-627, 1985. 